\title{
Challenges in launching multinational oncology clinical trials in India
}

\author{
Kamal S. Saini, Gaurav Agarwal', Ramesh Jagannathan ${ }^{2}$, Otto Metzger-Filho ${ }^{3}$, Monika L. Saini ${ }^{4}$, Khurshid Mistry ${ }^{5}$, \\ Raghib Ali', Sudeep Gupta ${ }^{7}$
}

\section{Abstract}

In the recent past, there has been an impressive growth in the number of clinical trials launched worldwide, including India. Participation in well-designed oncology clinical trials is of advantage to Indian healthcare system in general, and cancer patients in particular. However, the number of clinical trials being run in India is not commensurate with the cancer burden prevailing in the country. In this article, the authors investigate the reasons for this discrepancy, highlight critical bottlenecks, and propose ways to ameliorate the situation.

Key words: Cancer, challenges, clinical trials, delays, India, obstacles, oncology, regulatory, research, South Asia

\section{Introduction}

Clinical trials are an essential component of the drug development process. In recent decades, there has been a tremendous growth in the number of clinical trials worldwide, especially in the United States and Western Europe. Such studies have led to a remarkable progress in many different medical specialties, including oncology.

It has been estimated that $86 \%$ of clinical trials conducted in USA fail to recruit the required number of patients for several reasons. ${ }^{[1]}$ Partly as a result of this, the involvement of Latin America, Eastern Europe, South Africa, China, South-East Asia, and India has been increasing in clinical trials, providing trial sponsor access to a large number of ethnically diverse treatment-naïve patients for faster accrual of patients to their studies at lower costs, and also helping fulfill local regulatory requirements. ${ }^{[2]}$ Additional drivers of this trend include the rising cancer burden in developing countries, increasing economic importance of these markets, technically competent workforce, increasing experience of local

Breast International Group, Department of Medical Oncology, Jules Bordet Institute, Université libre de Bruxelles, ${ }^{4}$ Department of Anatomie Pathologique, Cliniques Saint Luc, Université catholique de Louvain, Brussels, Belgium, 'Department of Endocrine and Breast Surgery, Sanjay Gandhi Postgraduate Institute of Medical Sciences, Lucknow, Uttar Pradesh, ${ }^{2}$ Clinical Research, AstraZeneca Pharma India Ltd., Bangalore, Karnataka, Indian Cooperative Oncology Network, ${ }^{7}$ Department of Medical Oncology, Tata Memorial Centre, Mumbai, Maharashtra, India, ${ }^{3}$ Breast Oncology Center, Dana-Farber Cancer Institute, Boston, USA, 'INDOX Cancer Research Network, University of Oxford, Oxford, UK

Correspondence to: Dr. Kamal S. Saini,

E-mail:kamal.saini@bordet.be

\begin{tabular}{|l|l|}
\hline \multicolumn{2}{|c|}{ Access this article online } \\
\hline Quick Response Code: & Website: \\
\hline
\end{tabular}

clinical investigators, good medical infrastructure with international quality standards in many urban centres, pressure from patients for access to the latest treatment options, and the financial incentives (investigators fees, study grant, and infrastructure support) in many industry-sponsored trials. ${ }^{[3]}$ Importantly, clinical trials in India can cost less than half of what they would have cost to run in Western Europe or United States of America. ${ }^{[4]}$

There has been notable progress in the clinical research field in India in recent years. ${ }^{[5]}$ It has been estimated that the clinical trials business in India was worth approximately US\$ 250-300 million in 2009. ${ }^{[6]}$ The most active Indian cities based on the number of study sites of multinational sponsored clinical trials are ranked as follows: New Delhi, Bangalore, Mumbai, Hyderabad, Chennai, Pune, Ahmedabad, Ludhiana, Thiruvanantharum, Kolkata, and Vellore. ${ }^{[7]}$

India's capacity to take part in increasingly complex multinational studies is rapidly increasing. For example, India participated in the pivotal neoadjuvant and adjuvant lapatinib breast cancer studies [NeoALTTO (ClinicalTrials. gov Identifier NCT00553358), and ALTTO (ClinicalTrials. gov Identifier NCT00490139) respectively] that were coordinated by the Breast International Group (BIG) and involved the collection and transport of paraffin embedded tumor samples for tissue microarray construction, snap frozen tumour tissue for proteomics, and gene expression analyses, RNA/DNA extraction as well as blood for circulating tumour cells and proteomics.

Despite the impressive growth of clinical trials in India, its current performance is still far below its real potential. For example, there are presently a total of 129,099 trials listed on the clinicaltrials.gov registry, of which 64,459 involve the USA and only 2091 involve India. ${ }^{[8]}$ In the breast cancer domain, 4823 clinical trials are listed, and the entire South Asia region is involved in only 82 of these (70 in India, 10 in Pakistan, and 1 each in Bangladesh and Sri Lanka). In contrast, USA is involved in 2952 of these breast cancer trials, and even a tiny country like Belgium, with a population of 11 
million (half that of Mumbai city or less than 1\% of India) is participating in 214 such trials. The Clinical Trials Registry-India (CTRI) currently lists 77 breast cancer studies. ${ }^{[9]}$ While New Delhi is the tenth most populated city in the world, it was ranked as only the $158^{\text {th }}$ most active city globally in terms of clinical trials in 2008. ${ }^{[7]}$ In 2009, the Indian clinical trial industry conducted 240-260 trials sponsored by multinational pharmaceutical companies and another 180-200 trials by domestic ones. ${ }^{[6]}$ Thus, there is tremendous room for growth of clinical research activity in India.

India, which has about $17 \%$ of the world population, is involved in only about $1.5 \%$ of all clinical trials worldwide. In this article, the authors will highlight some of the reasons for this discrepancy, and focus on challenges and bottlenecks in launching multinational oncology clinical trials in India.

\section{Shortage of Personnel for Clinical Research in Oncology}

India, which has a total population of 1.25 billion, has only 1500 trained oncologists. ${ }^{[10]}$ The cancer patient-to-oncologist ratio in India is an abysmal 1600:1, compared to an estimated 100:1 in USA. It is understandable that oncologists in India have to shoulder a heavy clinical burden, leaving a little time for clinical research.

Running a clinical trial site requires the availability of several well-trained personnel in good clinical practice (GCP) methodology, including investigators, subinvestigators, research nurses, study coordinators, and data managers, as well as other medical specialists such as pathologists, radiologists, etc., Since clinical research is still a relatively nascent field in India, trained staff is not easily available at many hospitals. In addition, there is high turnover of junior staff members. ${ }^{[11]}$

The heterogeneous quality of supporting staff, lack of electronic medical records at many hospitals, and inadequate long-term follow-up of most cancer patients contribute to the perception among some global organizations that follow-up clinical data from some Indian sites may be of lower quality, especially in phase 4 (postapproval) studies. Clinical trial data per se, however, is usually of comparable quality to other regions. This is borne out by the increasing number of regulatory audits and inspections in India in which study conduct and data quality is found to be of acceptable quality. Nevertheless, when such inspection did reveal adverse findings, these were usually in the area of data credibility - inadequate and inaccurate records and failure to follow the protocol. ${ }^{[12]}$

\section{Underdeveloped Clinical Research Environment}

As a result of clinical overload, oncology training programs in India are forced to place greater emphasis on treatment of individual patients rather than on research. In oncology training programs of most institutions, there is no compulsory structured training in clinical trial methodology, GCP, or drug development. ${ }^{[13]}$ There is hardly any scientific input by Indian clinical researchers in designing multinational clinical trials. There is also a dearth of investigator-initiated trials in India with an analysis of 138 protocols finding that only three of them $(2.17 \%)$ were investigator initiated. ${ }^{[14]}$

The overwhelming patient numbers in major academic centers leaves little time for in-training clinicians to undertake basic, translational, or clinical research. In institutions such as the Sanjay Gandhi Postgraduate Institute of Medical Sciences (SGPGIMS), Lucknow, where it is mandatory for doctoral oncology students to undertake research and publish results before taking the exit exam, the candidate is expected to complete all data acquisition and analyses within 24 to 30 months. This time constraint usually leads them to undertake retrospective data analysis or short experimental studies as most prospective oncology clinical trials take much longer to complete.

The priority of most institutions is clinical care, and most available resources are preferentially directed toward patient treatment rather than research. Thus, even basic infrastructure required for clinical trials (like dedicated office space, communication and data management equipment and software, dedicated investigational and study drugs storage area, $-80^{\circ}$ deep freezer for sample storage, power backup, document archiving facility, institutional biobank, etc.) is often inadequate in many hospitals. There is usually little coordination or sharing of resources between different institutions, or even within different research teams in the same institution. As a result, duplication of equipment is commonly seen in the few research-oriented institutions in the country. Another disincentive is the fact that in many academic institutions, oncologists are not allowed to accept remuneration for their participation in clinical trials.

It was reported in 2005 that among the approximately 14,000 general hospitals in India, only about 150 had adequate infrastructure to conduct trials, and fewer than a dozen pathology laboratories were compliant with Good Laboratory Practice (GLP). ${ }^{[15]}$ There has been an improvement in the medical infrastructure since then, but even today, there is a lack of experienced and certified pathology laboratories with the capacity to provide central review of pathology and other prerandomization assays within the tight timelines dictated by large multinational clinical trials.

There has been some development of academic cooperative cancer groups in India, but this is not commensurate with the huge population of cancer patients. There is no academic or cooperative group data centre in India with significant experience in centrally managing the data from multinational oncology studies. Barring a few exceptions, the focus of oncology professional societies is more on continuing medical education (CMEs) and presentation of data/audits, rather than in the design and launch of clinical trials tailored to the needs of the Indian population. 
These factors have led to a relatively stunted clinical research environment in the oncology domain in India, and a lack of commitment to drug development.

\section{Limited Spending on Drug Research and Development}

The Indian pharmaceutical industry has shown impressive growth over the past two decades, as a result of economic reforms, patent-related legislation, and impressive growth of the domestic healthcare industry in general. India's global ranking in terms of pharmaceutical sales was 14 in 2005 and the country is expected to rise to the tenth position by $2015 .{ }^{[16]}$ The overall size of the Indian pharmaceutical market is currently estimated at approximately US\$ 11 billion. A bulk of these sales are accounted for by generics/formulations, and the overall research and development spend of Indian companies in new drug development is quite low compared to leading global pharmaceutical companies. India's ten largest drug firms together spent only about US \$ 480 million on $\mathrm{R}$ and $\mathrm{D}$ in 2008, mainly in areas of developing new formulations. ${ }^{[17]}$

Drug development research is mainly controlled and directed by the pharmaceutical company headquarters or affiliates in USA and Western Europe. In the last decade, there has been a trend to shift some R and D in clinical research to Asia, mainly to China. Nine out of the top ten pharmaceutical companies have dedicated research units in China ${ }^{[18]}$ In comparison, only three of the top ten pharmaceutical companies have dedicated $\mathrm{R}$ and $\mathrm{D}$ units in India.

While limited basic science-based drug discovery research is conducted by global pharmaceutical companies in India, some Indian pharmaceutical companies are beginning to increase their investment in drug discovery and development. Many leading domestic pharmaceutical companies as well as clinical contract research organizations (CROs) have been involved in the conduct of clinical trials in India for a decade or more. ${ }^{[19]}$

\section{Economic Factors}

According to a recent analysis of data from 2010, India spends only $4.1 \%$ of its GDP on health, compared to $9.6 \%$ for the United Kingdom [see Table 1]. ${ }^{[20]}$ This works out to a per capita total spending on health of $\$ 132$ for India versus $\$ 3480$ for United Kingdom (currency assumed to be international dollars as per purchasing power parity). $70.8 \%$ of all healthcare expenditure in India is borne by private spending, compared to only $16.1 \%$ for the United Kingdom.

Given the poor coverage of health insurance in India, the majority of cancer patients have to pay out-of-pocket for their treatment. This severely limits their purchasing power and makes expensive targeted therapies like the anti-HER2 monoclonal antibody trastuzumab unaffordable to the majority of breast cancer patients in India. ${ }^{[2]}$ Thus, innovator companies that include India in multinational trials get relatively meager returns by marketing expensive targeted therapies in India as the pool of insurance-covered patients is quite small. Many countries from emerging regions that contribute patients for clinical trials are denied the post-trial benefits that should accrue to them, mainly for economic reasons. ${ }^{[3]}$ This model, where the risks are borne by individuals without benefits for the larger society, could be considered exploitative. ${ }^{[1]}$ There is also significant pressure from patients, politicians, civil society members, and the media to keep cancer drug prices low.

Hence, the current economic realities of the Indian market may not be attractive enough to compel global pharmaceutical companies to include India in multinational oncology trials.

\section{Regulatory and Legal Factors}

In 2005, the Indian government amended the "Schedule Y" of the Indian Drugs and Cosmetics Act (1940). During the same year, India adopted a new patent regime compliant with Trade-Related Intellectual Property Rights of the World Trade Organization. ${ }^{[22]}$ There has been a significant increase in multinational clinical trial activity in India since these regulatory reforms. ${ }^{[23]}$

Seeking approvals from the different regulatory authorities in different countries is one of the main factors that impact the timelines of the launch of multinational clinical trials. In a retrospective analysis of startup times for Phase III oncology studies, the median number of weeks between the final protocol approval (FPA) date and the first site initiated (FSI) date was 55, 31.5, 40.2, and 35.6 weeks in Brazil, Russia, India, and China, respectively. ${ }^{[24]}$ The screen failure rate (i.e., the percentage of patients who, through the screening process, were disqualified from participating in the study) was $20 \%, 20.5 \%, 32.3 \%$, and $10.2 \%$, while the dropout rate (i.e. median percentage of patients per study who left the study after having been randomized into it) was $8.3 \%, 18.1 \%, 18.2 \%$, and $10.6 \%$ in Brazil, Russia, India, and China, respectively. According to an analysis of prospectively collected data related to the launch of the ALTTO trial, Metzger-Filho et al. found that the median time for regulatory approval was 236 days in South America, 52 days in Europe, 26 days in North America, and 62 days in Asia-Pacific (manuscript submitted for publication).

In India, there is a multiplicity of overlapping authorities governing clinical trials and drug development. While the authority to grant permission to conduct clinical trials in India rests with the Central Drug Standard Control Organization (CDSCO) headed by the Drugs Controller General of India (DGCI), ${ }^{[25]}$ other bodies involved in the process include the New Drugs Advisory Committee (NDAC), Drug Technical Advisory Board (DTAB), Indian Council of Medical Research (ICMR), and Directorate General of Foreign Trade (DGFT). These organizations may not be optimally 
Table 1: Key health statistics from selected countries (source: World health organization)

\begin{tabular}{|c|c|c|c|c|c|c|}
\hline Country & $\begin{array}{c}\text { Health spending, } \\
\% \text { of GDP }\end{array}$ & $\begin{array}{l}\text { Private spending } \\
\text { on health as \% of } \\
\text { all health spending }\end{array}$ & $\begin{array}{l}\text { Gov spending } \\
\text { on health as \% } \\
\text { of all spending }\end{array}$ & $\begin{array}{c}\text { Per capita gov } \\
\text { spending on } \\
\text { health (PPP int. \$) }\end{array}$ & $\begin{array}{l}\text { Nurses and } \\
\text { midwives, per } \\
10,000 \text { pop }\end{array}$ & $\begin{array}{c}\text { Doctors, per } \\
10,000 \text { pop }\end{array}$ \\
\hline Afghanistan & 7.6 & 88.3 & 1.6 & 5 & 5 & 2.1 \\
\hline Bangladesh & 3.5 & 66.4 & 7.4 & 19 & 2.7 & 2.95 \\
\hline Belgium & 10.7 & 25.3 & 15.1 & 3008 & 5.37 & NA \\
\hline Bhutan & 5.2 & 13.2 & 10.5 & 239 & 3.2 & 0.23 \\
\hline Brazil & 9 & 53 & 7.1 & 483 & 64.19 & 17.64 \\
\hline China & 5.1 & 46.4 & 12.1 & 203 & 13.8 & 14.15 \\
\hline India & 4.1 & 70.8 & 3.6 & 39 & NA & 6.49 \\
\hline Maldives & 6.3 & 39.5 & 8.6 & 281 & 44.5 & 15.95 \\
\hline Nepal & 5.5 & 66.8 & 7.9 & 22 & 4.6 & 2.1 \\
\hline Pakistan & 2.2 & 61.5 & 3.6 & 23 & 5.6 & 8.13 \\
\hline Russia & 5.1 & 37.9 & 8 & 620 & 85.2 & 43.089 \\
\hline Sri Lanka & 2.9 & 55.3 & 5.8 & 66 & 19.3 & NA \\
\hline United Kingdom & 9.6 & 16.1 & 16 & 2919 & 101.33 & 27.43 \\
\hline United States & 17.9 & 46.9 & 22.4 & 4437 & NA & 24.22 \\
\hline
\end{tabular}

$\mathrm{GDP}=$ Gross domestic product, Gov=Government, $\mathrm{PPP}=$ Purchasing power parity, Int=International, Pop=Population, NA=Not available

staffed and hence not able to efficiently process the increasing number of applications, as a result of which the approval timeline for a clinical trial can range from 5 to 8 months. ${ }^{[26]}$ In 2011, the total approvals for clinical trials in India dropped to 98, compared with 224 in 2010. ${ }^{[27]}$ However, a recent paper has reported that as a result of staff recruitment and other reforms, the median review period has reduced from 16 to 10 weeks [Figure 1]. ${ }^{[28]}$

The ICMR guidelines for export of bio-materials or genetic materials are perceived by some trialists as stringent and restrictive, and could discourage collaborative research. ${ }^{[29]}$ However, the CDSCO is reportedly aiming to simplify the clearance for export of biological samples of clinical trials, in collaboration with the DGFT. ${ }^{[28]}$

Registration of clinical trials on the CTRI website has been made mandatory since 2009 , and is a step in the right direction.

\section{Ethics Committees and Institutional Review Boards}

Ethics Committees (ECs) in India often lack training, experience, and standard operating procedures (SOPs), and do not have a proper composition or adequate representation. ${ }^{[30,31]}$ It has been estimated that fewer than 40 ECs in India are properly constituted. ${ }^{[32]}$ There is a scarcity of individuals with the appropriate background and expertise to be members of ECs. In addition, there is a reluctance of qualified individuals to serve on these committees, infrequent meetings, heavy workload, inadequate space, and lack of administrative support. ${ }^{[1]]}$ For investigators working in smaller towns or in nonacademic centers, it is usually quite difficult to get access to ECs.

Of 145 randomized clinical trials (RCTs) published in Indian journals in 2007-2008, only 107 were reported to have taken EC clearance. ${ }^{[33]}$ Indian journal editors must make such declaration mandatory before accepting clinical trial results for publication.

There is no restriction in the ICMR guidelines on principal investigators also being members of ECs, ${ }^{[34]}$ and this could potentially lead to conflicts of interest. A survey covering $20 \mathrm{ECs}$ in India revealed deficiencies in composition, quorum, and review of insurance documents and clinical trial agreements, reinforcing the need for providing specific training to EC members. ${ }^{[35]}$ Such training should ideally cover ethical principles as well as the philosophical, legal, and practical dimensions of research ethics. ${ }^{[36]}$

Only about half of the large hospitals have Institutional Review Boards (IRBs), and even these usually do not have well-documented SOPs, and often lack the expertise to critically evaluate protocols. ${ }^{[37]}$ Information about conflicts of interest is neither sought nor voluntarily provided by investigators. ${ }^{[15]}$ Currently, Indian regulatory authorities are mulling stricter laws to curb unethical trials. ${ }^{[38]}$

\section{Miscellaneous Factors}

A hostile environment is created by media reports of alleged exploitation of poor patients from India by multinational pharmaceutical corporations. ${ }^{[39,40]}$ The coverage is often sensational and inaccurate. ${ }^{[41]}$ Often, the Indian media portrays "experimental medicine" as exploitation of patients. There is inadequate comprehension of ethical issues and scientific nuances involved in clinical research by the lay public and even sections of the media, health care planners, bureaucracy, judiciary, and the government. A communication gap between researchers and the mass media is a serious problem worldwide. ${ }^{[42,43]}$

In a large, complex, and socioculturally evolved country like India, dozens of local languages are spoken in its different parts. This necessitates the certified translation of clinical trial material into several languages, impacting timelines, and budget.

There is considerable variation among (and even within) 
cancer centres on standard therapy for cancer, resulting from a lack of institutional or national guidelines. In addition, multidisciplinary teams do not exist in many Indian cancer hospitals. ${ }^{[4]}$

In India, there are no uniform policies for compensating injuries to research participants. ${ }^{[45]}$ Recently, draft guidelines $^{[46]}$ on compensation to clinical trial participants have been issued, leading to concerns in the research community. ${ }^{[4]}$ Views of all stakeholders should be incorporated before finalization of these guidelines.

\section{Suggestions for Improving the Situation}

- Capacity building and training of clinical trial investigators, EC members, and regulators to improve their clinical-research-related skillsets. Organizations like the Indian Cooperative Oncology Network (ICON) and The Forum for Ethics Review Committees of India (FERCI) can play a crucial role in this effort.

- Continue with efforts to expand the number of trained doctors in India. ${ }^{[48]}$

- Medical curriculum should include clinical research and medical statistics.

- It must become mandatory to publish findings of clinical studies that have been carried out in India within a fixed timeframe, even if the results are "negative." "[49]

- Laws related to data protection and intellectual property rights must be strengthened further. ${ }^{[50]}$

- Functioning of ECs and IRBs should be subjected to external audits.

- Regulatory authorities need to frame fair rules to ensure that new drugs tested on Indians will be made

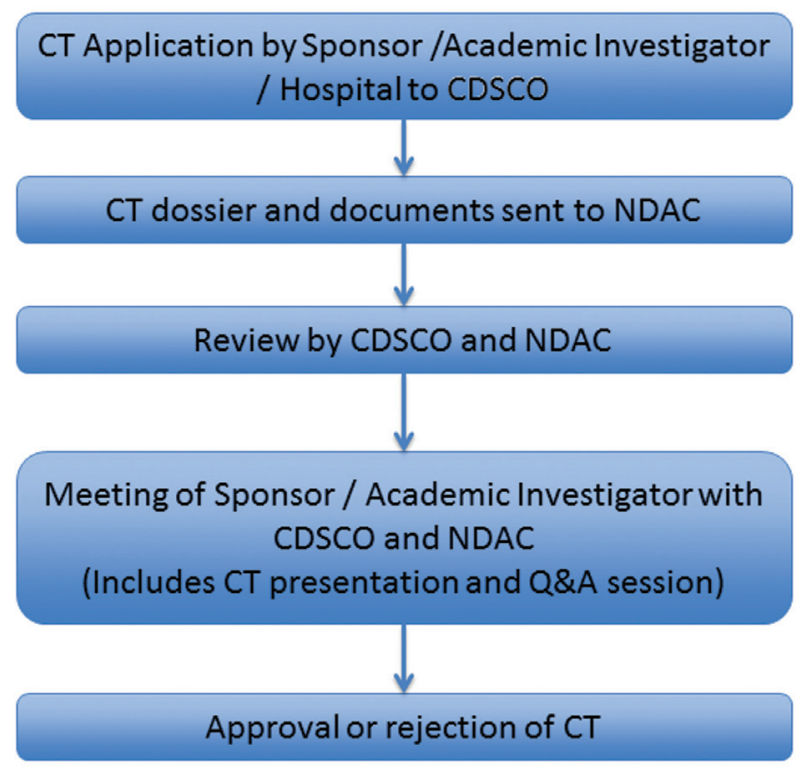

Figure 1: Indicative clinical trial application review process in India, which takes approximately 4 to 8 months in total. (CT: Clinical Trial, CDSCO: Central Drugs Standard Control Organization, NDAC: New Drug Advisory Committee, Q\&A: Question and Answer) (Source: adapted from www.cdsco.nic.in) available in the country at affordable prices. ${ }^{[3,15,51]}$

- Formation of patient advocacy groups should be encouraged and patient representatives should be included in ECs.

- A systematic mechanism of dissemination of information about available clinical trials should be implemented.

\section{Conclusion}

India has gained much from participating in multinational clinical trials, including establishment of GCP norms and SOPs, improvement in physical infrastructure and laboratories, and provision of employment to many clinical research staff. ${ }^{[52]}$ Despite some well-publicized cases of unethical trials, ${ }^{[1]}$ the vast majority of clinical trials have brought great benefit to the Indian healthcare system in general, and cancer patients in particular. Participation in multinational clinical trials has allowed Indian cancer specialists to obtain a first-hand experience with new drugs in a strictly monitored environment, and to determine the efficacy and toxicity of these drugs among the different Indian ethnicities. Such experience will help build their capacity to design their own trials in future.

As India's population becomes more affluent and adopts "western" lifestyles (smoking, sedentary jobs, increased fat consumption, and decreased physical activity), as the mean life expectancy lengthens, the incidence of cancer is expected to significantly increase in the coming decades. Clinical trials adapted to the pressing research questions that are pertinent to local conditions will be needed, ${ }^{[5]}$ particularly for those cancers that are commoner in India than in the West, for example, gallbladder, cervical, and oral malignancies. Administrators, regulators, and course directors of academic oncology teaching programs must keep these factors in mind, and encourage the creation of an environment where clinical research can flourish.

\section{Disclaimer}

The views expressed in this article are those of the authors and do not necessarily represent the views of, and should not be attributed to, the organizations or institutions for which they work.

\section{References}

1. Maiti R, Raghavendra M. Clinical trials in India. Pharmacol Res 2007;56:1-10.

2. Schwartsmann G, Ratain MJ, Cragg GM, Wong JE, Saijo N, Parkinson DR, et al. Anticancer drug discovery and development throughout the world. J Clin Oncol 2002;20 Suppl 18:47S-59.

3. Mano MS, Rosa DD, Dal Lago L. Multinational clinical trials in oncology and post-trial benefits for host countries: Where do we stand? Eur J Cancer 2006;42:2675-7.

4. Eudaric A. Managing clinical logistics for clinical trials in emerging markets. Available from: www.parexel.com/index.php/download_ file/view/69/. [Last accessed on 2012 Jul 15].

5. Gupta S, Nag S, Dawood S. Challenges and opportunities in the design and implementation of breast cancer clinical trials in developing countries. Clin Investig 2012;2:579-87.

6. Jayakumar PB. Clinical trials losing the plot in India. Available from: 
http://www.business-standard.com/india/news/clinical-trialslosingplot-in-india/419660/. [Last accessed on 2012 Jul 15].

7. Karlberg J. Development of sponsored clinical trials in Asia. Available from: http://www.ctmagnifier.org/2008/M2008_1_05.aspx. [Last accessed on 2012 Jul 15].

8. Available from: http://clinicaltrials.gov/. [Last accessed on 2012 Jul 15].

9. Available from: http://ctri.nic.in/Clinicaltrials/login.php. [Last accessed on $2012 \mathrm{Jul}$ 15].

10. Noronha VT, Jamshed A, Hai MA, Wattegama S, Baral RP. A fresh look at oncology facts on south central Asia and SAARC countries. South Asian J Cancer 2012;1:1-4.

11. Thatte UM, Bavdekar SB. Clinical research in India: Great expectations? J Postgrad Med 2008;54:318-23.

12. Bhatt A. Indian clinical trials: Paradigm shift from speed to quality? Perspect Clin Res 2012;3:1-3.

13. Julka P. Clinical trials in India-dilemmas for developing countries. Available from: http://www.ecronacunova.com/pdf/ whitepapers/Whitepaper-CT\%20in\%20India.pdf. [Last accessed on 2012 Jul 15].

14. Bavdekar SB. Informed consent documents submitted for initial review: What do they state about compensation for injured research participants? Indian J Med Sci 2009;63:455-60.

15. Nundy S, Gulhati CM. A new colonialism?--Conducting clinical trials in India. N Engl J Med 2005;352:1633-6.

16. Kumra G. McKinsey and company Indian Pharma 2015: Unlocking the potential of the Indian pharmaceutical market. Available from: http://www.mckinsey.com/locations/india/mckinseyonindia/ pdf/india_pharma_2015.pdf. [Last accessed on 2012 Jul 15].

17. Global Pharma looks to India: Prospects for growth. Available from: http://www.pwc.com/en_GX/gx/pharma-life-sciences/pdf/ global-pharma-looks-to-india-final.pdf. [Last accessed on 2012 Jul 15].

18. Evolving $\mathrm{R}$ and $\mathrm{D}$ for emerging markets. Nat Rev Drug Discov 2010;9:417-20.

19. Drabu S, Gupta A, Bhadauria A. Emerging trends in contract research industry in India. Contemp Clin Trials 2010;31:419-22.

20. Available from: http://www.guardian.co.uk/news/datablog/2012/ jun $/ 30 /$ healthcare-spending-world-country?intcmp $=239$. [Last accessed on 2012 Jul 15].

21. Ghosh J, Gupta S, Desai S, Shet T, Radhakrishnan S, Suryavanshi P, et al. Estrogen, progesterone and HER2 receptor expression in breast tumors of patients, and their usage of HER2-targeted therapy, in a tertiary care centre in India. Indian J Cancer 2011;48:391-6.

22. Singh S. Indian pharma enters the global arena. Cell 2007; 128:811-4.

23. Srinivasan S, Loff B. Medical research in India. Lancet 2006;367:1962-4.

24. Available from: http://www.decisionview.com/sites/default/ files/analyst_report_pdfs/decisionview_enrollment_optimization_ report_mar2012.pdf. [Last accessed on 2012 Jul 15].

25. Available from: http://164.100.47.5/newcommittee/reports/ englishcommittees/committee\%20 $\% 20$ health\%20and\%20 family\%20welfare/59.pdf. [Last accessed on 2012 Jul 20].

26. Available from: http://articles.economictimes.indiatimes. com/2012-07-10/news/32618689_1_new-drugs-drug-regulationdrug-controller-general. [Last accessed on 2012 Jul 20].

27. Available from: http://economictimes.indiatimes.com/news/ news-by-industry/healthcare/biotech/healthcare/hit-by-redtape-clinical-trial-companies-eye-south-east-asia-for-expansion/ articleshow/14077184.cms. [Last accessed on 2012 Jul 20].

28. Gupta YK, Padhy BM. India's growing participation in global clinical trials. Trends Pharmacol Sci 2011;32:327-9.

29. Available from: http://www.touchbriefings.com/pdf/17/ pt031_r_4_bakhle\%5B1\%5D.pdf. [Last accessed on 2012 Jul 20].

30. Kadam $\mathrm{R}$, Karandikar S. Ethics committees in India: Facing the challenges! Perspect Clin Res 2012;3:50-6.
31. Tharyan P. Ethics committees and clinical trials registration in India: Opportunities, obligations, challenges and solutions. Indian J Med Ethics 2007;4:168-9.

32. Available from: http://www.who.int/bulletin/ volumes/86/8/08-010808/en/index.html. [Last accessed on 2012 Jul 18]

33. Tharyan P, George AT, Kirubakaran R, Barnabas JP. Reporting of methods was better in the Clinical Trials Registry-India than in Indian journal publications. J Clin Epidemiol 2012;66:10-22.

34. Pauranik A, Bharani A, Bhargava S, Bajpai A, Jain H, Verma P. Misleading report on clinical trials in India. Lancet 2012;379:1947-8.

35. Taur SR, Bavdekar SB, Thatte UM. Survey of ethics committee protocol approval letters: Compliance with Schedule Y/ICMR guidelines 2006. Indian J Med Ethics 2011;8:214-6.

36. Brahme R, Mehendale S. Profile and role of the members of ethics committees in hospitals and research organisations in Pune, India. Indian J Med Ethics 2009;6:78-84.

37. Available from: http://www.ijppsjournal.com/Vol2Suppl1/215R. pdf. [Last accessed on 2012 Aug 3].

38. Jayaraman K. India mulling stricter laws to curb unethical trials. Nat Med 2012;18:182.

39. Available from: http://m.indianexpress.com/news/10-die-perweek-in-drug-trials-in-india/971834/. [Last accessed on 2012 Aug 2].

40. Available from: http://articles.timesofindia.indiatimes.com/201106-06/india/29624892 1 clinical-trials-drug-controller-generaldcgi. [Last accessed on 2012 Aug 2].

41. Ramamurthy NV. Inept media trials of clinical trials. Perspect Clin Res 2012;3:47-9.

42. Yuji K, Narimatsu H, Tanimoto T, Komatsu T, Kami M. Sharing information on adverse events. Lancet 2011;377:1654.

43. Campion EW. Medical research and the news media. N Engl J Med 2004;351:2436-7.

44. Saini KS, Taylor C, Ramirez AJ, Palmieri C, Gunnarsson U, Schmoll HJ, et al. Role of the multidisciplinary team in breast cancer management: Results from a large international survey involving 39 countries. Ann Oncol 2012;23:853-9.

45. Thatte UM, Kulkarni-Munshi R, Kalekar SA. Review of policies for injuries to research participants in India. J Med Ethics 2009;35: 133-9.

46. Kang G. Putting patients first: Draft guidelines for compensation for research-related injury in clinical trials in India. Indian J Med Ethics 2012;9:77-9.

47. Pramesh CS, Badwe RA. Will the proposed compensation guidelines for research-related injury spell the death knell for clinical research in India? J Postgrad Med 2012;58:156-8.

48. Available from: http://zeenews.india.com/news/nation/bonanzaover-5-000-new-medical-seats-created_784825.html.[Last accessed on 2012 Aug 6].

49. Arora RS, Arora P, Prabhu V, Eden T. Subsequent publication rate of studies from India presented at the annual congresses of SIOP. Pediatr Blood Cancer 2012;59:956-8.

50. Malhotra P. The impact of TRIPS on innovation and exports: A case study of the pharmaceutical industry in India. Indian J Med Ethics 2008;5:61-5.

51. Dandona L. Clinical trials in India: Balancing economic opportunity with the public health context. Natl Med J India 2006;19:57-9.

52. Raina V. Doing cancer trials in India: Opportunities and pitfalls. Ann Oncol 2005; 16: 1567-8.

How to cite this article: Saini KS, Agarwal G, Jagannathan R, Metzger Filho O, Saini ML, Mistry K, et al. Challenges in launching multinational oncology clinical trials in India. South Asian J Cancer 2013;2:44-9. Source of Support: Nil. Conflict of Interest: None declared. 